\title{
Perspective
}

\section{Emphysema: the challenge of the remodelled lung}

\author{
R Blundell, ${ }^{1,2}$ DJ Harrison' and WAH Wallace ${ }^{1 *}$ \\ 'Directorate of Pathology, The Royal Infirmary of Edinburgh, 5 I Little France Crescent, Edinburgh, EHI 6 4SA, UK \\ 2 Institute of Forensic Studies, University of Malta, Msida MSD06, Malta
}

*Correspondence to:

Dr WAH Wallace, Directorate of

Pathology, The Royal Infirmary of

Edinburgh, 51 Little France

Crescent, Edinburgh, EHI 6 4SA,

UK.

E-mail:

william.wallace@/uht.scot.nhs.uk

Received: 17 June 2003

Revised: 16 July 2003

Accepted: I October 2003

\begin{abstract}
Emphysema is recognized as the component of chronic obstructive airways disease that is responsible for airways obstruction. Different patterns of emphysema are, however, recognized, suggesting possible different pathogenetic processes within the lung. This, coupled with the associated idea of susceptibility factors to the development of emphysema, has led to studies of genes that may be involved in the defence of the lung from proteolytic and oxidative damage. These studies have been driven by the goal of finding a treatment for emphysema, but appear to have lost sight of the fundamental remodelling of the lung that has occurred in patients with emphysema and the fact that it is not a single morphological entity. Copyright $\subset 2004$ John Wiley \& Sons, Ltd.
\end{abstract}

Keywords: emphysema; pathology; molecular biology; gene therapy

\section{Historical background}

Emphysema, as a major component of chronic obstructive pulmonary disease (COPD), is a significant cause of morbidity and mortality, although perhaps only a quarter of smokers develop clinically significant emphysema [1]. The presence and severity of emphysema in patients with COPD, whether assessed microscopically or by computed tomography (CT), has been shown to correlate with decreased gas transfer and the fall in $\mathrm{FEV}_{1}$ [2] that characterizes this condition and it is believed to be the pathological cause of the fixed irreversible airways obstruction seen in these individuals due to loss of alveolar wall attachments to small bronchioles in the distal lung [3,4].

Emphysema was first defined as 'a condition of the lung characterized by an increase beyond the normal in size of the airspaces distal to the terminal bronchiole either from dilation or from destruction of their walls' [5]. This original definition did not distinguish between over-inflation and the disruption of the lung architecture, which occurs in smoking-related emphysema. In 1962, the definition suggested was 'a condition of the lung characterized by abnormal, permanent enlargement of airspaces distal to the terminal bronchioli accompanied by destruction of their walls' [6]. This was further modified in 1985, by adding 'accompanied by destruction of their walls and without obvious fibrosis' [7].

Whilst useful, these definitions are actually an oversimplification. To fulfil the definition of emphysema, three points must be taken into account, ie the size of airspace, evidence for a destructive process, and an assessment that fibrosis is minimal [8]. None of the definitions was accompanied by criteria that allowed the concept of 'normal airspace size' to be defined.
Similarly, in the 1985 definition, the term 'without obvious fibrosis' is clearly a conceptual statement and may give rise to problems in relationship to the presence of smoking-related fibrosis in lungs where both inflammatory cells and fibrosis are frequently encountered. Furthermore, changes occur in ageing lungs [9] that are qualitatively similar to emphysema in smokers, suggesting either that clinically significant emphysema is at the severe end of normal tissue loss through ageing (similar to bone and neurones) or that ageingrelated loss of lung tissue is the benign end of a spectrum of disease resulting from environmental exposure to toxic chemicals [10].

The pathological appearances of the lungs in patients with COPD are well described in pathology textbooks [11] and for several decades emphysema has essentially been a pathologist's territory, with great effort being directed towards classification into anatomic types. Thus, centriacinar emphysema (CAE) (synonyms preacinar, proximal acinar, centrilobular) was envisaged as the result of immediate injury to respiratory bronchioles and adjacent tissues, essentially an active destructive process. The abnormal airspaces are found in association with respiratory bronchioles, though in more severe cases virtually the whole acinar unit may be involved. In most cases of CAE, there is a distinct distribution with gradation of severity from the apex of the lung towards the base. Panacinar emphysema (PAE) (synonyms periacinar, distal acinar), by contrast, is a more diffuse process, at least in its early stages, characterized by remodelling of the lung, loss of elastic recoil, and increased capacity. Abnormally large airspaces are found evenly distributed across the acinar unit. Adjacent acinar units are usually involved to a similar degree, giving a confluent appearance to the cut surface of the lung, with extensive areas being 
involved. There is no obvious macroscopic pattern to the distribution of the disease in the lung. In paraseptal emphysema, the abnormal airspaces run along the edge of the acinar unit, but only where it abuts against a fixed structure such as the pleura, a vessel or a septum. Two other types of emphysematous changes were described, scar emphysema (synonym irregular), where the emphysematous spaces are found around the margins of a scar, and bullous emphysema, in which areas of emphysema are locally overdistended to produce a lesion which, if superficial, stands proud of the pleural surface [12].

These differences, with the associated implication that the aetiology and pathogenesis may differ, have been largely forgotten by researchers because no reliable functional or clinically significant differences have been identified that correlate with structure. Patients with COPD do vary in their clinical behaviour and patterns of respiratory failure, but no relationship between these and the pattern of emphysema present has been demonstrable [13]. Nor has any link between any of the recognized risk factors for emphysema and the pattern of disease been identified. Thus, the term 'emphysema' has passed into common usage as if it is a homogeneous disease.

\section{Possible aetiology and pathogenesis}

The absence of any association with risk factors or clinical features does, however, raise the possibility that the development of emphysema and its different pathological patterns could be the result of interaction between external risk factors and intrinsic host susceptibility factors. The concept of susceptibility factors was first suggested by the observation that emphysema occurs in patients with $\alpha_{1}$-anti-trypsin $\left(\alpha_{1}\right.$-AT) deficiency [14] and that this was exacerbated by concomitant smoking. $\alpha_{1}$-AT is a major plasma inhibitor of proteolytic enzymes and since such enzymes can induce experimental 'emphysema' in animal models, it seemed plausable that the association of $\alpha$-protease deficiency with emphysema [15] was the result of unopposed proteolytic activity in the lung giving rise to the generally accepted protease/anti-protease theory of injury. This was further refined when the enzyme elastin was also found to have the potential to cause experimental 'emphysema'. Thus, the protease/antiprotease theory was evolved into the elastase/antielastase theory of the pathogenesis of emphysema, with neutrophil elastase (NE) being the major enzyme implicated [16-19]. Macrophages are another potential source of protease enzymes and are commonly seen in a centriacinar position in smokers, although not always concomitant with emphysema [20]. It has been postulated that these cells, possibly regulated by T-lymphocytes, release macrophage serine elastase, which is much more efficient in degrading lung interstitium, and that this may be more important [21].
Whilst clearly applicable to animal models and the human situation in $\alpha_{1}$-AT deficiency, this theory has not been fully substantiated for the generality of human emphysema. Refinement of the theory has therefore occurred, in particular recognizing the role of oxidants. Each puff of cigarette smoke generates $10^{15}-10^{17}$ free radicals [22,23]. In addition, oxidative metabolism of other compounds in both bronchiolar and alveolar epithelium, especially by smokeinducible cytochrome p450's, generates even more radicals $[23,24]$. Oxygen free radicals damage many structures and cause immediate neutrophilic infiltration, as well as directly inhibiting protease inhibitors [25]. In addition, nicotine may prolong the life span of neutrophils and thus potentiate lung damage [26]. So, the theory of protease/anti-protease imbalance has been modified by adding the effects of oxidants and possibly by invoking different elements of both innate and adaptive immunity.

There still remains, however, the question of why only a proportion of smokers develop emphysema. Within the extracellular fluid in the lung, there is a bias towards the quenching of oxidants and free radicals. Uric acid, reduced glutathione, ascorbate, sacrificial sulphoproteins which can be oxidized and discarded, extracellular superoxide dismutase (SOD3), catalase, and glutathione peroxidase all serve to protect the epithelial lining. Within the cells, in addition, there are protective antioxidant enzymes that by conjugation, cleavage of peroxides or deapoxidation remove toxic species [27]. Could differences in this antioxidant protection be important in determining whether or not emphysema occurs?

\section{Oxidative stress: the balancing act}

A number of enzymes involved in the activation, metabolism, and detoxification of cigarette components are polymorphic. In some situations, this genotypic variation is reflected by a difference in functional enzyme activity. The range of enzymes is large, substrate specificity frequently overlaps, and there may be considerable redundancy between different enzymes.

Cytochrome p450 1A1 (CYP1A1) has a rare variant $(<5 \%)$ which is thought to result in increased inducibility and hence activity of the enzyme. CYP1A1 metabolizes many components of cigarette smoke to active radicals and the enzyme is itself induced by cigarette smoke [28]. Several studies have linked the rare variant of CYP1A1 genotype to increased susceptibility to lung cancer in smokers. However, these studies highlight one of the problems inherent in studies of emphysema and lung cancer, namely that both diseases may co-exist. A similar study repeated in a UK population where the presence of emphysema and cancer was taken into consideration revealed a very small association between CYP1A1 genotype and susceptibility to emphysema, but not to cancer. However, 
the relative risk was small and of doubtful significance in the population as a whole [29].

Similarly, a detoxification enzyme, glutathione Stransferase M1 (GSTM1), a member of a detoxification family conjugating free radical species to reduce glutathione and also directly engaged in protection against peroxidation injury, is polymorphic [30]. Approximately $50 \%$ of the population have a deletion of part of or the entire gene at both alleles and are therefore GSTM1 null [31]. Again, several studies have associated GSTM1 null with increased risk of lung cancer, but once again if the presence or absence of emphysema is taken into account, the association is with emphysema rather than lung cancer [32]. Although GSTM1 is expressed in lung, it is present at a higher concentration in liver, raising the possibility that much injury inflicted on the lung by cigarette smoke may be the result of systemic metabolism.

Microsomal epoxide hydrolase (mEPHX) is an enzyme involved in the metabolism of highly reactive epoxide intermediates. Four distinct mEPHX alleles exist which arise because of the presence of two point mutations in the gene. An exon 3 T-to-C mutation changes Tyr 113 to His, reducing enzyme activity by at least $50 \%$ (slow allele). The second, an A-to-G transition mutation in exon 4 of the gene, changes His 139 to Arg, producing an enzyme with a putative increase in activity of at least $25 \%$ (fast allele). The wild-type allele is characterized by the absence of these two changes, but the presence of both mutations in a rare mEPHX allele produces a hydrolase with normal activity. It has been demonstrated that there is an association between genetically defined polymorphisms in mEPHX activity and susceptibility to COPD and emphysema and this suggests that highly reactive epoxide intermediates may play a role in the initiation and progression of the character tissue abnormalities seen in emphysema [33]. Polymorphisms of the mEPHX gene may be an important risk factor in lung disease associated with oxidative stress, consistent with the direct effects of cigarette smoke components.

We appear to have come some distance in understanding the external environmental factors that lead to emphysema and possible genetic risk factors that may influence who develops it. One of the challenges, however, in further understanding the role and interaction of these factors will be in explaining the divergent patterns of lung remodelling that occur in these patients which, as described, is not homogeneous.

\section{Implications for treatment}

Much of the interest in this type of research in the last few years has been driven by an interest in developing strategies or agents that might interfere with these proposed pathogenetic mechanisms. So, what are the implications for the treatment of emphysema from this research? What is clear is that the most effective preventative measure to reduce the incidence of emphysema is for people not to smoke cigarettes, or to stop if they do smoke [1]. The disease is slowly progressive and there is evidence that the rate of loss of lung tissue reduces to 'normal levels' if cigarette smoking is stopped [34]. It remains unclear, however, whether approaches based on modulating inflammation or modulating the oxidant/antioxidant balance will be feasible.

Techniques under evaluation include the use of exogenously administered pharmacological agents, but also gene therapy with the aim of local production of anti-elastase/elastase inhibitors in the treated lung [35-39]. There still remains the problem, so far ignored, that the pathological basis of emphysema and fixed airways obstruction is the result of lung remodelling with the loss of alveolar walls and support of the small peripheral bronchioles. All the proposed treatments are, at most, likely to prevent or modify future remodelling in patients who continue to smoke, but it would seem unlikely that even with stem cell therapy (for discussion see ref 40) lost alveolar tissue will be restored. In many respects, a more realistic, simpler, and cheaper alternative for the vast majority of patients with emphysema is to prevent disease progression by smoking cessation. The alternative approach, which appears to be where we may be heading, is the development of agents which at best will protect the lung from damage, whilst permitting the patient to continue smoking!

\section{References}

1. Strachan DP. Epidermology: a British perspective. In Chronic Obstructive Pulmonary Disease, Calverley P, Pride N (eds). Chapman \& Hall: London, 1995; 47-68.

2. MacNee W, Gould G, Lamb D. Quantifying emphysema by CT scanning: clinicopathological correlates. Annu N Y Acad Sci 1991; 624: 179-194.

3. Lamb D, McLean A, Gillooley M, Warren PM, Gould GA, Macnee W. Relation between distal airspace size, bronchiolar attachments and lung function. Thorax 1993; 48: 1012-1017.

4. Nagai A, Yamawaki I, Takizana T, Thurlbeck WM. Alveolar attachments in emphysema of human lungs. Am Rev Respir Dis 1991; 144: 888-891.

5. Ciba Foundation Guest Symposium. Terminology, definitions and classification of chronic pulmonary emphysema and related conditions. Thorax 1959; 14: 286-299.

6. American Thoracic Society. Chronic bronchitis, asthma and pulmonary emphysema. Am Rev Respir Dis 1962; 85: 762-768.

7. Snider GL, Kleinerman J, Thurlbeck WM. The definition of emphysema. Am Rev Respir 1985; 132: 182-185.

8. Lamb D. Pathology. In Chronic Obstructive Pulmonary Disease, Calverley P, Pride N (eds). Chapman \& Hall: London, 1995; 9-34.

9. Gillooly M, Lamb D. Airspace size in lungs of lifelong nonsmokers: effects of age and sex. Thorax 1993; 48: 39-43.

10. Lang MR, Fiaux GW, Gillooly M, Stewart JA, Hulmes DJ, Lamb D. Collagen content of alveolar wall tissue in emphysematous and non-emphysematous lungs. Thorax 1994; 49: 319-326.

11. Lamb D. Chronic bronchitis, emphysema and the pathological basis of chronic obstructive pulmonary disease. In Spencer's 
Pathology of the Lung (5th edn), Hasleton PS (ed). McGraw-Hill: New York; 1996; 597-630.

12. Thurlbeck WM. The pathobiology and epidemiology of human emphysema. J Toxicol Environ Health 1984; 13: 323-343.

13. Nagai A, West WW, Thurlbeck WM. The National Institutes of Health Intermittent Positive-Pressure Breathing trial: pathology studies. II. Correlation between morphologic findings, clinical findings, and evidence of expiratory air-flow obstruction. Am Rev Respir Dis 1985; 132: 946-953.

14. Gadeu JE, Pacht ER. The protease/antiprotease balance within the human lung: implications for the pathogenesis of emphysema. Lung 1990; 168: 552-564.

15. Rudolphus A, Kramps JA, Mauve I, Dijkman JH. Intratracheallyinstilled antileukoprotease and alpha-1-proteinase inhibitor: effect on human neutrophil elastase-induced experimental emphysema and pulmonary localization. J Histochem 1994; 26: 817-824.

16. Chow CK. Cigarette smoking and oxidative damage in the lung. Ann N Y Acad Sci 1993; 686: 289-298.

17. Fujita J, Nelson NL, Daughton DM, et al. Evaluation of elastase and antielastase balance in patients with chronic bronchitis and pulmonary emphysema. Am Rev Respir Dis 1990; 142: 57-62.

18. King MB, Campbell EJ, Gray BH, Hertz MI. The proteinaseantiproteinase balance in alpha-1 proteinase inhibitor-deficient lung transplant recipients. Am J Respir Crit Care Med 1994; 151: 966-971.

19. Travis J, Pike R, Imamura T, Potempa J. The role of proteolytic enzymes in the development of pulmonary emphysema and periodental tissue. Am J Respir Crit Care Med 1995; 151: 925-929.

20. Wallace WAH, Gillooley M, Lamb D. Intra-alveolar macrophage numbers in current smokers and non-smokers: a morphometric study of tissue sections. Thorax 1992; 47: 437-440.

21. Tetley TD. Macrophages and the pathogenesis of COPD. Chest 2002; 121: (5 Suppl): 156S-159S

22. Church DF, Pryor WA. Free radical chemistry of cigarette smoke and its toxicological implications. Environ Health Perspect 1985; 64: $111-126$.

23. Hoffman D, Hecht SS. Advances in tobacco carcinogenesis. Handbook Exp Pharmacol 1990; 94: 63-102.

24. Smith CAD, Smith G, Wolf CR. Genetic predisposition to cancer: polymorphisms in xenobiotic metabolising enzymes. Eur J Cancer 1994; 30A: $1921-1936$

25. Rahman I, MacNee W. Role of oxidant/antioxidant in smoking induced lung diseases. Free Radical Biol Med 1996; 21: 669-689.

26. Aoshiba K, Nagai A, Konno K. Nicotine prevents a reduction in neutrophil filterability induced by cigarette smoke exposure. Am J Respir Crit Care Med 1994; 150: 1101-1107.

27. Choi AM, Alam J. Heme oxygenase-1: function, regulation and implication of a novel stress-induced protein in oxidant-induced lung injury. Am J Respir Cell Mol Biol 1996; 15: 9-19.

28. McLemore TL, Adelberg S, Liu MC, et al. Expression of CYP1A1 gene in patients with lung cancer: evidence for cigarette smoke-induced gene expression in primary pulmonary carcinomas. J Natl Cancer Inst 1990; 82: 1333-1339.

29. Cantlay AM, Lamb D, Gillooley M, et al. Association between the CYP1A1 gene polymorphism and susceptibility to emphysema and lung cancer. JCP - Clin Mol Pathol 1995; 48: M210-M214.

30. Nakajima T, Elovaara E, Anttila S, et al. Expression and polymorphism of glutathione S-transferase in human lungs: risk factors in smoking-related lung cancer. Carcinogenesis 1995; 16: $707-711$.

31. Harrison DJ, Cantlay AM, Rae F, Lamb D, Smith CA. Frequency of glutathione S-transferase M1 deletion in smokers with emphysema and lung cancer. Hum Exp Toxicol 1997; 16: 356-360.

32. Buhl R, Meyer A, Vogelmeier C. Oxidant-protease interaction in the lung. Prospects for antioxidant therapy. Chest 1996; 110: 267-272.

33. Smith CAD, Harrison DJ. Association between polymorphism in gene for microsomal epoxide hydrolase and susceptibility to emphysema. Lancet 1997; 350: 630-634.

34. Seth JM, Rochester CL. Smoking and chronic obstructive pulmonary disease. Clin Chest Med 2000; 21: 67-86.

35. Lucey EC, Goldstein RH, Stone PJ, Snider GL. Remodeling of alveolar wall after elastase treatment of hamsters. Results of elastin and collagen mRNA in situ hybridization. Am J Respir Crit Care Med 1998; 158: 555-564.

36. Massaro GD, Massaro D. Retinoic acid treatment abrogates elastase-induced pulmonary emphysema in rats. Nature Med 1997; 3: $675-677$.

37. Morris SM, Thomas KM, Rich CB, Stone PJ. Degradation and repair of elastic fibres in rat lung interstitial fibroblast cultures. Anat Rec 1998; 250: 397-407.

38. Shinguh Y, Yamazaki A, Inamura N, et al. Biochemical and pharmacological characterization of FR134043, a novel elastase inhibitor. Eur J Pharmacol 1998; 345: 299-308.

39. Wilcke JT, Dirksen A. The effect of inhaled glucocorticosteroids in emphysema due to alpha 1-antitrypsin deficiency. Respir Med 1997; 91: 275-279.

40. McBride S, Rannie D, Harrison DJ. Gene transfer to adult human lung tissue ex vivo. Gene Ther 2000; 7: 675-678. 